\title{
Implementation of Energy Stored For TC Nano Grid With Power Factor Correction Converter
}

\author{
S. Nirmalraj, Godwin Immanuel, Santhi Mary Antony, Ramya, Suruthi
}

\begin{abstract}
In the recent years DC Nano grid has become more popular which serves as a replacement for the AC-grid due to the DC characterized loads and more distributed power generation sources. The advantage of using DC Nano-grid is that, it provides safety by providing reliable grounding for residential. In this paper, a dual Buck-Boost AC/DC converter to be used in the united grounding configuration, based on DC Nano-grid with three terminal outputs on existing low power AC system is designed by using the proposed converter. The main aim of the work is to design a converter with high power factor and less steady state error. To reduce the errors and faults unidirectional grounding is implemented and the power factor is corrected using phase lock loop.The modeling of the system and the working of the proposed converter are explained and validated with Simulations results.
\end{abstract}

Keywords : Solar panel, Stepper motor, Microcontroller, DC to DC converter, ANFIS technique, Light Dependent Resistor.

\section{INTRODUCTION}

The main purpose of this work is the optimal integration of DC nano grid based on the AC source various power generations. By converting $\mathrm{AC}$ consumption into DC consumption we need a DC nano grid. Most of electric power consumed in DC. Electric motor, heating element, electronics, electric car and virtually any all electrical machinery consumes electricity in DC. Even some high efficient 3 phase AC electric motor cannot complete with (Brushed or even brush- less) DC motor in term of efficiency and simplicity. The capacity of transmission defined by the size of the overhead cable is not restricted by the inductance ort the capacitance values. Since transmission has to be done over larger cities or open sea, using the full cross section of the conductor is essential. A digital control accurate and instant control of the active power flow. AC power transmission mostly consists of 3 wires of respective phase(R-S-T) wire, which equal to the capacity of

Revised Manuscript Received on October 30, 2019.

* Correspondence Author

S.NirmalRaj*, Assistant professor in Sathyabama Institute of Science and Technology Chennai, India.

D.Godwin Immanuel, Professor, Sathyabama Institute of Science and Technology, Chennai.

A.Santhi Mary Antony, Assistant Professor in department of EEE in Sathyabama Institute of Science and Technology.

D.Ramya, Assistant Professor in department of EEE in Sathyabama Institute of Science and Technology.

Suruthi, BE degree in Electrical \& Electronic Engineering from Sathyabama Institute of Science and Technology Chennai, India

(c) The Authors. Published by Blue Eyes Intelligence Engineering and Sciences Publication (BEIESP). This is an open access article under the CC BY-NC-ND license (http://creativecommons.org/licenses/by-nc-nd/4.0/)
1wireifDCtransmitted.Inshort, hardware cost of high voltage DC for long distance transmission is approximately $1 / 3$ of its counterpart when we integrate DC power line to any existing AC power grid [3], DC power can generate very fast modulation and can damp the oscillation effect hence the AC system, thus maintain the stability of the whole system. So far there are no clear disadvantages of DC power transmission except for the fact that most of existing electric power system is using Hi-voltage. And its option is made somewhere in 1880-90's where DC-DC converter was far beyond the practical technology, back then. Now that DC-DC converter is becoming more and more very efficient and inexpensive. Invention of Vanadium- Vanadium flow battery further simplifies the DC voltage conversion. The distributed power generation has become widely attractive because of the lack of energy [9]-[10] and the environmental problems which are as a result of burning the fossil energy. [7]-[8]. The problem in connecting the number of distributed generation systems, like photovoltaic systems to the AC power system through various kinds of power converters are voltage rise, current distortion and safety issues [1],[5]\&[6].

\section{PROPOSED METHOD}

In proposed system, unidirectional grounding is implemented to reduce the faults that might occur on the grid. Also it's controlled with the help of power factor correction system which is implemented by using phase lock loop control technique. The process is explained both using hardware and also using simulation.

The above figure fig 1 represents the block diagram of proposed method. In proposed system, unidirectional grounding is implemented to reduce the faults that might occur on the grid. Also it's controlled with the help of power factor correction system which is implemented by using phase lock loop control technique. The process is explained both using hardware and also using simulation. Further, the stimulation of proposed work has been carried out using MATLAB/SIMULINK and experimental values are validated with simulation parameters.

The block diagram of the proposed method is shown in Fig 1. The converter works in boost mode when E1 and E2 are greater than the amplitude of the grid voltage. In order to provide safety, the DC Nano-grid provides reliable grounding for the residential loads like the low voltage AC power system. Out of the three typical grounding configurations for a DC Nano-grid, the united 


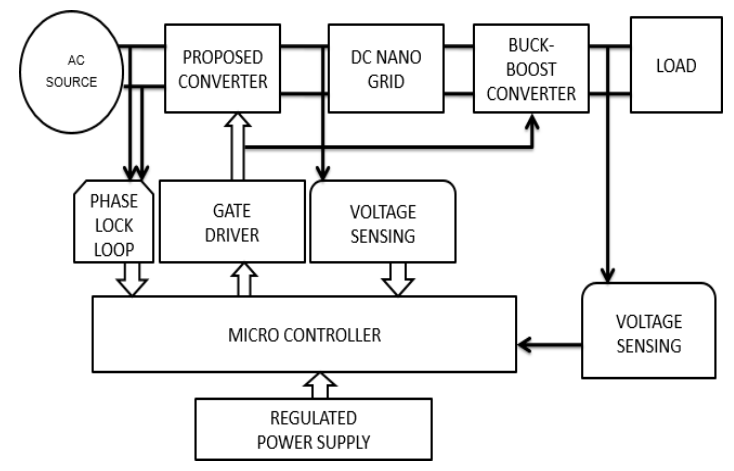

Fig. 1.Block diagram of proposed method grounding configuration has its own specifications to AC/DC converters[2],[3]. In this project, a dual Buck-Boost AC/DC converter to be used in the united grounding configuration, based on DC Nano-grid with three terminal outputs on existing low power AC system is proposed. The detailed working of the converter is explained as follows.

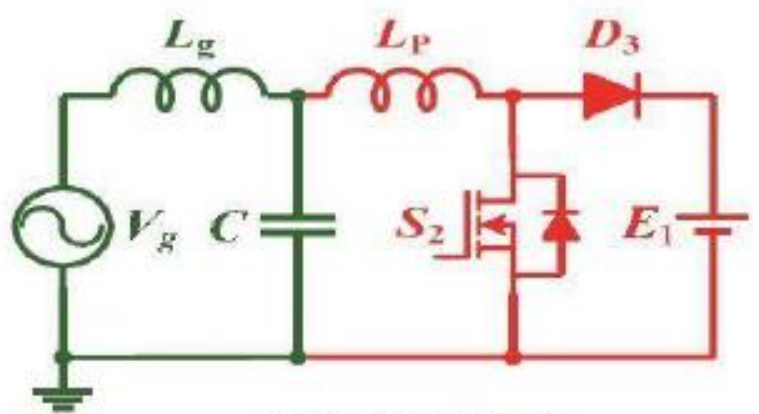

(a) During $T_{1}$ and $T_{3}$

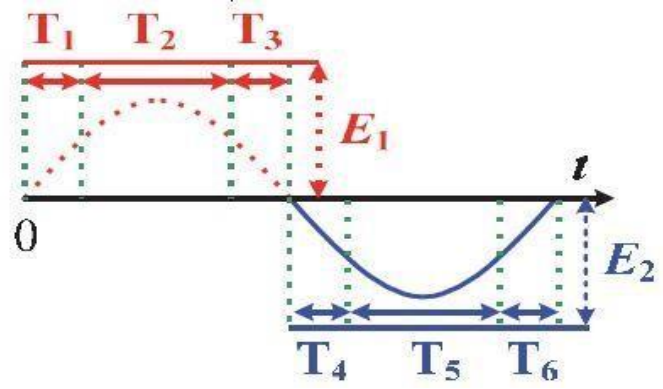

Fig. 2. switching selection.

The switch selection is shown in Fig 2. Overall switching selection timing

- In one complete cycle split into six stages.

- For positive cycle - T1,T2,T3

- For negative cycle - T4,T5,T6

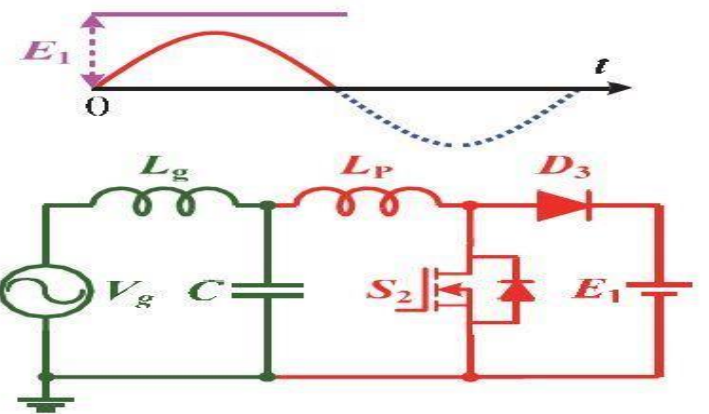

Fig. 3.Positive cycle

Fig 3 shows positive cycle. During the positive cycle (AT T2)
- For positive cycle the red zone will in active state the switch S1 will be ON

- And the voltage is controlled by the switch S2 the PWM will generate in the $\mathrm{T} 1$ and $\mathrm{T} 3$ time period.

- Each author profile along with photo (min 100 word) has been included in the final paper.

- Final paper is prepared as per journal the template.

- Contents of the paper are fine and satisfactory. Author (s) can make rectification in the final paper but after the final submission to the journal, rectification is not possible.

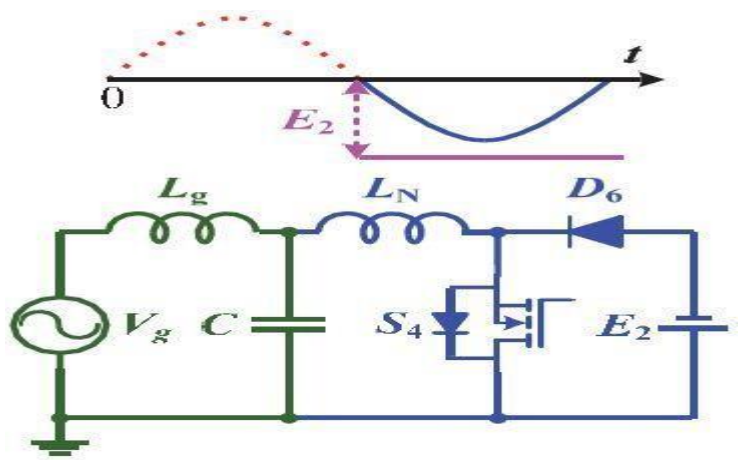

Fig. 4.Positive cycle

Fig 4 shows negative cycle. During the negative cycle (AT T5)

- For negative cycle the blue zone will in active state the switch S3 will be ON

- And the voltage is controlled by the switch s4 PWM will generate in the T4 and T6 time period

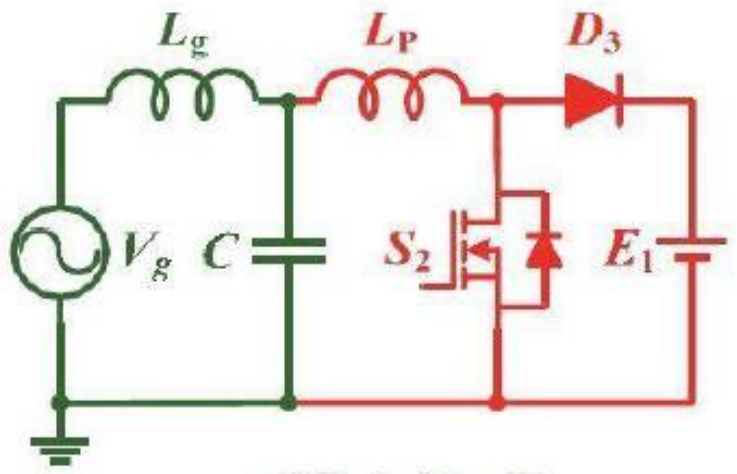

(a) During $T_{1}$ and $T_{3}$

Fig. 5.Time interval T1 and T3

During $\mathrm{T} 1$ and $\mathrm{T} 3$ as shown in Fig 5

- The rectifier works in the boost mode during the interval T1 and T3.

- The Voltage of Inductor Lp could be described as:

$$
\begin{gathered}
\mathrm{VLP} 1(\mathrm{t})=\mathrm{Vc}(\mathrm{t}) \\
\operatorname{VLP} 2(\mathrm{t})=\mathrm{Vc}(\mathrm{t})-\mathrm{e} 1(\mathrm{t})
\end{gathered}
$$

- WhereVLP1 is the voltage of Lp when the switch S1 is on, and VLP2 is the voltage of LP when the switch S1 is off. 
The fig 6 shows the proposed converter circuit diagram. In the circuit, when a12v DC supply is given to diode D1, switch S1 will be on and voltage will be controlled by the switch S2. The PWM will be generated in the time $\mathrm{t} 1, \mathrm{t} 3$ time periods. During the negative cycle $(-12 v)$, the switch S3 will be $\mathrm{ON}$ and the voltage is controlled by the switch $\mathrm{S} 4$ and PWM will generate in the $t 4$ and $t 6$ time periods.E1and E2 is combined and is grounded .If the voltage at E1 is zero, E2 will supply power and to share current with E1. If the voltage at E2 is zero, the reverse happens. i.e. E1 supplies powertoE2, whichalsosharesthecurrentwithE1|

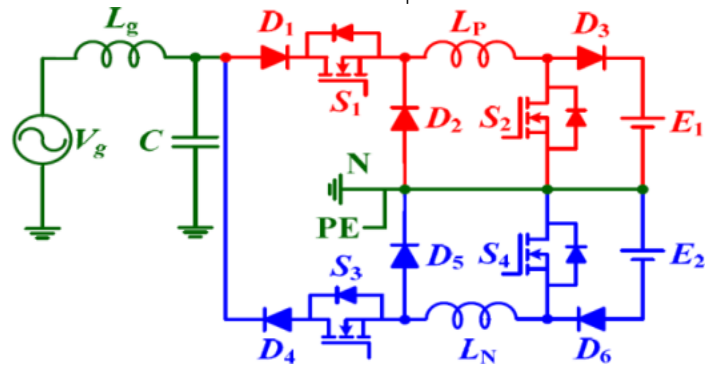

Fig. 6. proposed converter

\section{SIMULATION RESULTS}

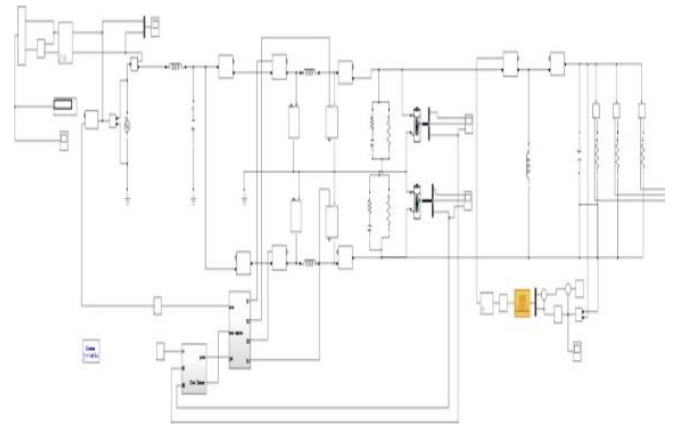

Fig. 7. Fuzzy simulation

\section{- Algorithm:}

- The above figure 7 is the circuit diagram for fuzzy simulation. The proposed dc Nano grid system consists of the following component in the above simulation it can be seen that

- The power factor correction block consists of a calculation block and a storage block. The calculation block measures the power factor correction and stores it in the storage block. The storage block stores the power factor correction values so that it can be referred, when it's required.

- The input source is the input power supply, i.e. $230 \mathrm{~V}$ which is being transferred to $12 \mathrm{~V}$ using a step down transformer.

- The LC filter is used for filtering the harmonic signal of a particular frequency.

- The microcontroller present inside the grid is used for deducting the switching modes i.e. if the signal is in positive or negative cycle.

- The fuzzy logic controller (FLC) is responsible for controlling the buck boost converter.

- The output block produces the output for the dc nano grid $(12 \mathrm{~V})$ and for the load output (24V).

In the fuzzy controller the steady state error (steady state error means if V set 24 as output voltage it will set it as
$23.5 \mathrm{~V}$. It won't reach $24 \mathrm{~V}$ ) will be high, synchronization is not possible but over voltage problem will not occur.

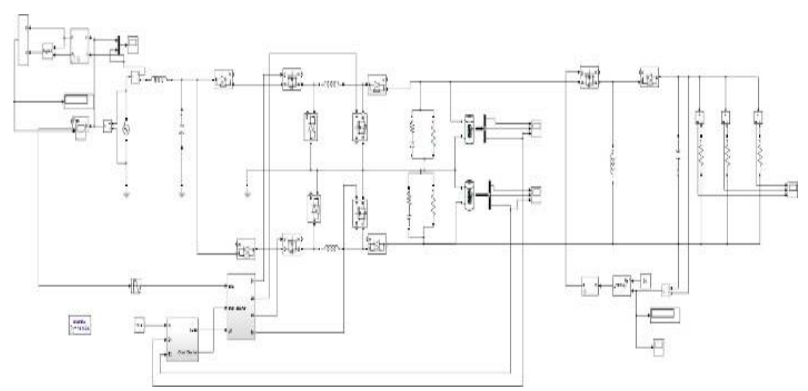

Fig. 8. PID simulation

The above figure fig 8 is the circuit diagram for PID simulation. In PID over shoot will be there (overshoot is nothing but if we saidoutputvoltageis24, in PI, PID voltage will rise the value and will set as 27 or so.

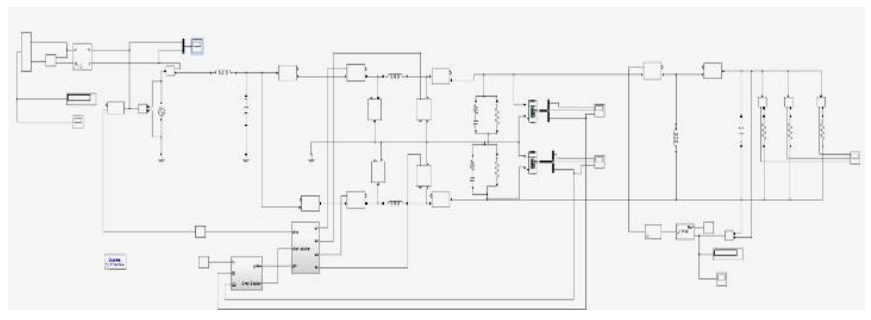

Fig. 9. PI simulation

The above figure fig 9 is the circuit diagram for PI simulation. In PI also over shoot will be there (over shoot is nothing but if we said output voltage is 4 , inPIPID voltage will rise the value and will set it as 27 or so).

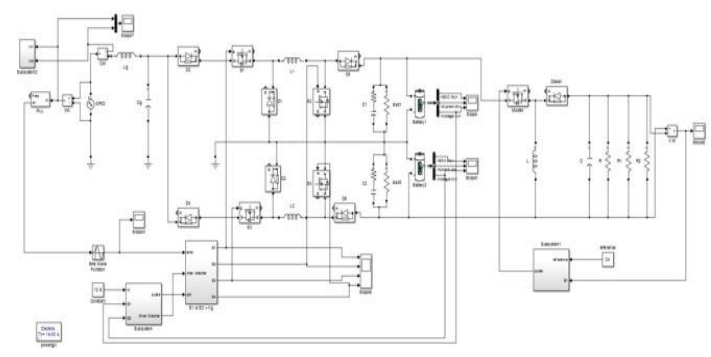

Fig. 10. Overall simulation

Figure 10 show the overall simulation. In this simulation, it can be seen that power factor correction is done. This is possible only because we use a DC nano grid which keeps the voltage constant [4]. In case of AC nano grid it won't be possible.

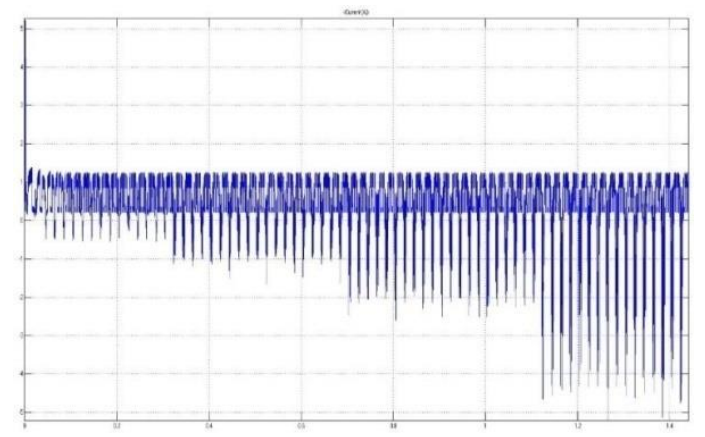

Fig. 11. Battery 1 current

Published By: 


\section{Implementation of Energy Stored For TC Nano Grid With Power Factor Correction Converter}

The above graph figure. 11 represent the battery 1 current. The graph is plotted between current and time.

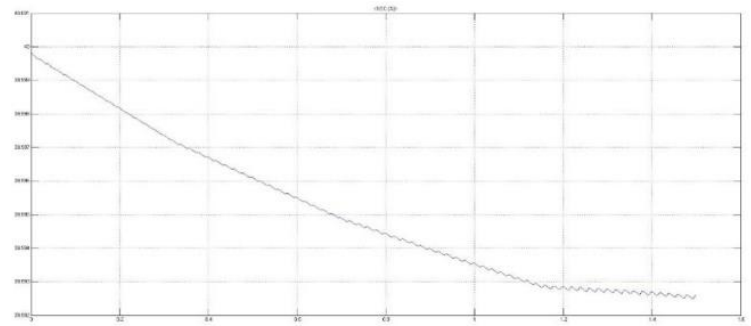

Fig. 12. Battery 1 SOC

The above graph figure 12 represents the state of charge. The graph is plotted between state of charge and SOC.

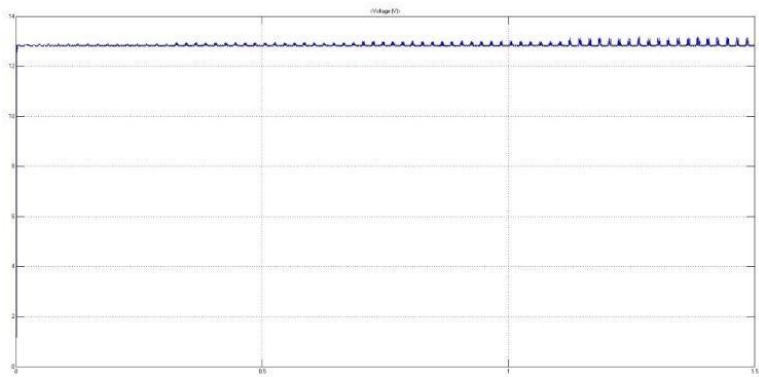

Fig. 13. Battery 1 Voltage

The above figure 13 represents the battery 1 voltage. The graph is plotted between voltage and time.

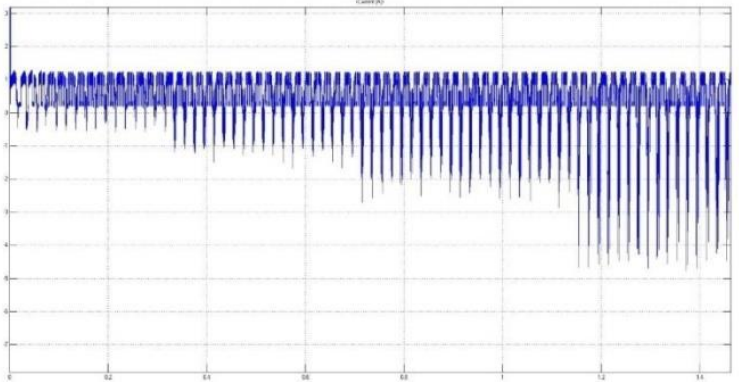

Fig. 14. Battery 2 current

The above figure14 represent the battery 2 current. The graph is plotted between current and time.

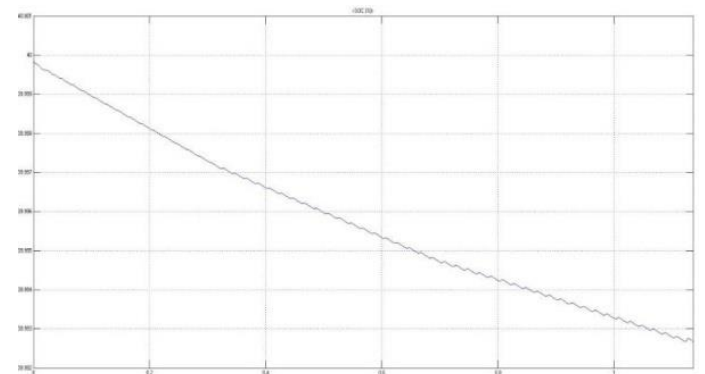

Fig. 15. Battery 2 SOC

The above figure. 15 show the battery 2 SOC. The graph is plotted between current and time.

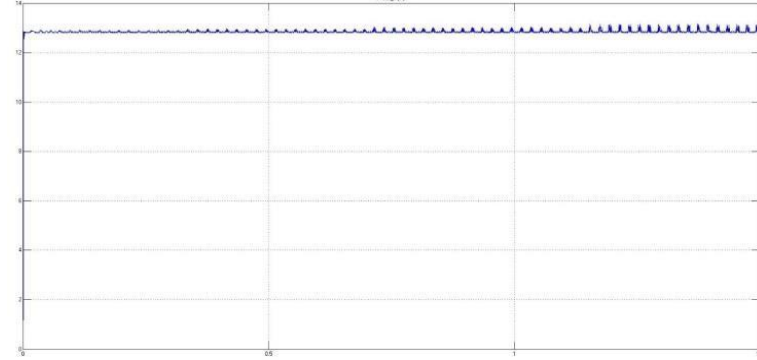

Fig. 16. Battery 2 voltage

The above graph Figure. 16 represent the battery 2 voltage. The graph is plotted between voltage and time.

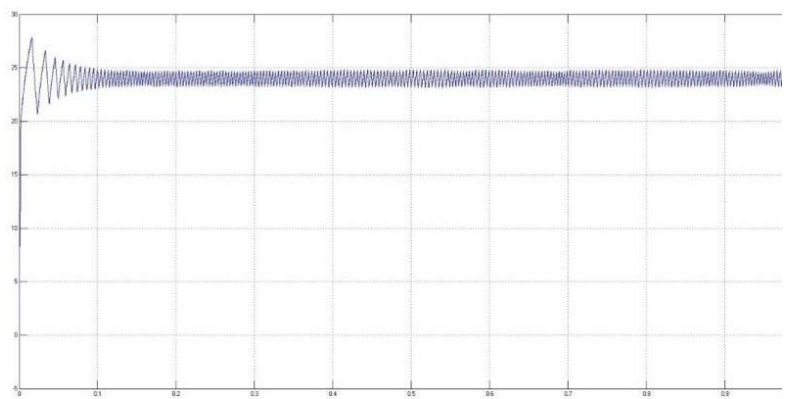

Fig. 17. Input voltage and current

The above figure 17 is the input voltage and current wave form.

Fig. 18. Power factor

The above Figure18 show the power factor.

\begin{tabular}{|l|r|r|rr|}
\hline & \multicolumn{2}{|c|}{ PI } & PID & \multicolumn{2}{|c|}{ Propo } \\
\hline $\begin{array}{l}\text { Settling } \\
\text { time }\end{array}$ & \multicolumn{2}{|c|}{ 2s } & $1.5 \mathrm{~s}$ & \multicolumn{2}{|c|}{0.3} \\
\hline $\begin{array}{l}\text { Power } \\
\text { factor }\end{array}$ & 75 & 0.9 & 0.98 & \multicolumn{2}{|c|}{0.9} \\
\hline $\begin{array}{l}\text { Steady } \\
\text { state } \\
\text { error }\end{array}$ & \multicolumn{1}{|c|}{$1 \mathrm{~V}$} & $0.8 \mathrm{~V}$ & \multicolumn{2}{|c|}{0.2} \\
\hline
\end{tabular}

After analysis between PI, PID and Fuzzy, the fuzzy controller is the best in this converter since both the settling time and the error rate factors are the least for the FLC shown in Table 1.

\section{CONCLUSION}

This paper proposes a high efficient DC Nano grid which is achieved by the united grounding configuration that facilitates the direct connection of the DC Nano grid with the low AC power system using the same ground line. The advantage of this grounding configuration is that, it helps to construct a DC Nano-grid based on the original low voltage AC power system.

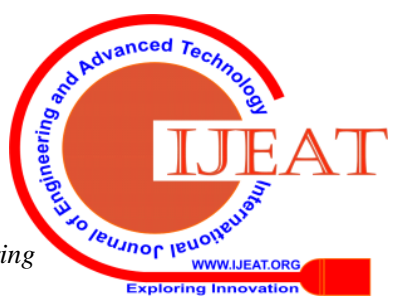


Comparing the Proposed united grounding configuration with the existing unidirectional groundings used in the DC Nano grids, the united grounding configuration is highly efficient in terms of settling time, power factor and steady state error. The proposed converter has the less settling time , higher power factor and a less steady stare error when compared to the existing converters. The system is also cost effective.

\section{REFERENCES}

1. Yatsuki S., Wada K., Shimizu T.et al. A novel AC photovoltaic module system based on the impedance-admittance conversion theory[C].IEEEPESC'2001, 2001, pp.2191-2196.

2. Wang, Houqing, et al. "A coupled-inductor-based buck-boost AC-DC converter with balanced dc output voltages." IEEE Transactions on Power Electronics 34.1 (2018): 151-159.

3. Xue, Yong, Jiamei Deng, and Shuangbao Ma. "Power flow control of a distributed generation unit in micro-grid." 2009 IEEE 6th International Power Electronics and Motion Control Conference. IEEE, 2009.

4. Wu, Weimin, et al. "A dual-buck-boost ac/dc converter for dc nanogrid with three terminal outputs." IEEE Transactions on Industrial Electronics 64.1 (2016): 295-299.

5. Xiao Jing-liang, $\mathrm{Xu}$ Zheng1, LIN Chong, HEShao- qiang. Optimaldesign of photovoltaic arrays under partial shading[J]. Proceedings ofthe CSEE, 2009, 29(11),pp.119-124.

6. A.Santhi MaryAntony, Dr.Godwin Immanuel, "A Novel Single Phase bridgelessAC/DC PFC converter for Low Total Harmonics Distortion and High PowerFactor", International Journal of Power Electronics and Drive System (IJPEDS) , Vol. 9,No. 1, March 2018, pp. 17-24, ISSN: 2088-8694.

7. A.Santhi MaryAntony , Dr.Godwin Immanuel, "Bridgeless Isolated Cuk-Converter withBumpless Control for Reduced THD and Power Factor Correction", Journal of AdvancedResearch in Dynamical \& Control Systems (2018), Vol. 10, 09-Special Issue, pp. 1357 -1363.

8. Nirmalraj, S., and T. Vigneswaran. "A Novel cascaded image transform by varying energy density to convert an image in to sparse." Indian J. Sci. Technol 8.8 (2015): 766-770.

9. D. Godwin Immanuel, G. Selva kumar, and ,C. Christober Asir Rajan, "A MultiObjective Hybrid Differential Evolution Algorithm assisted Genetic AlgorithmApproach for Optimal Reactive Power and Voltage Control", International Journal ofEngineering and Technology,Vol.6, Issue-1, pp.199-203,2014.

10. D. Godwin Immanuel, Dr. C. Chritober Asir Rajan "An Genetic Algorithm Approachfor Reactive Power Control Problem", in proceedings of the Circuits, Power andComputing Technologies (ICCPCT), International IEEE Conference, pp. 74-78,March 2013.

\section{AUTHORS PROFILE}

S.NirmalRaj obtained B.E degree in Electronics and communication from Periyar University Salem, India in 2004. He obtained his M.tech degree in VLSI Design from Sathyabama Deemed University Chennai, India in 2006. He is pursuing his Ph.D. in image processing. He is currently working as an Assistant professor in Sathyabama Institute of Science and Technology Chennai, India. His research interest includes Image compression, Image fusion, Compressive signal, sparse signals processing.

D. Godwin Immanuel was born in Nagercoil, Tamilnadu. He completed his B.E degree in Electrical and Electronics Engineering in Manonmaniam sundarnar university, Tirunelveli. He later completed his Masters in Power system Engineering in Annamalai University and completed his Phd in Sathyabama University. He has published more than 40 papers in various Journals and Conferences. His research interest includes Power Sytem Optimization problems

A.Santhi Mary Antony has obtained her B.E degree in Electrical \& ElectronicEngineering from Madras University 2003. She received her M.E degree in PowerElectronics and Industrial Drives from Sathyabama University in 2005. She is pursuingher Ph.D. degree in Electrical Engineering from Sathyabama University. She has 13 yearsof teaching experience. Now, she is working as an Assistant Professor in department ofEEE in Sathyabama Institute of Science and Technology. She has published more than 17papers in the research areas of Power Electronics, A.C machines, D.C Machines and Control Systems
D.Ramya has received her BE degree in Electrical \& Electronic Engineering from Manonmaniam Sundaranar University 2002. She received her ME degree in Power Electronics and Industrial Drives from Sathyabama Universityin 2004. She is pursuring her Ph.D. degree in Electrical Engineering from Sathyabama University. She has 14yearsof teaching experience. Now, she is working as an Assistant Professor in department ofEEE in Sathyabama Institute of Science and Technology. She has published more than 15papers in the research areas of Power Electronics, A.C Machines and D.C Machines.

Suruthi has received her BE degree in Electrical \& Electronic Engineering from Sathyabama Institute of Science and Technology Chennai, India in 2019. 